Sādhanā, Vol. 12, Part 3, March 1988, pp. 289-305. (C) Printed in India.

\title{
Management of the Indian space programme
}

\author{
Y S RAJAN \\ Indian Space Research Organization. ISRO Headquarters, F Block, \\ Cauvery Bhavan, Kempegowda Road, Bangalore 560 009, India
}

\begin{abstract}
A brief survey of some salient aspects of the management of the Indian Space Programme is made, with special stress on the period 1972-1984. In view of the complexity of the subject matter, some major elements are addressed without necessarily offering conclusions on all the issues or the questions posed. Some major policy initiatives during the period 1972-1984 are also described.
\end{abstract}

Keywords. Indian space programme: national space programme management; space policy.

\section{Introduction}

The benefits from space activities have now become widely known in the country. In fact there is worldwide recognition of the importance of space activities not only for the developed nations but in particular for the developing countries. Such a recognition, even at well-informed levels, did not exist in the country when India formally organized its modest space effort through the establishment of the Indian National Committee for Space Research (INCOSPAR) in 1962. In November 1963 the first sounding rocket was launched from the Thumba Rocket Launching Station (TERLS) near Trivandrum. The founders of the Indian space programme recognized the potential for the immense benefits from space technology even in the early 1960s, when humanity was just ushering in the space era. Early ideas about possible space applications of relevance to India can be found in a number of writings and speeches by Dr Sarabhai, a selection of which have been brought out in a publication by the Indian Space Research Organization (ISRO) (ISRO 1979). The early ideas were mainly centred around the utilization of satellites for television and developmental education, meteorology, and remote sensing for natural resources management. The programme also included development and launch of sounding rockets for space science research. Though international cooperation dominated in the early years, careful stress was placed on self-reliance. Nucleii of trained manpower were formed at laboratories that were then part of INCOSPAR but were constituted into ISRO in 1969. It is not the purpose of this article

This paper has been published in the author's personal capacity and the views cxpressed here are not necessarily those of the Organisation. 
to dwell on these details. The beginnings. however, need to be noted to understand the management of the programme during the seventies and the early eighties.

Organisationally, the activities of ISRO were under the overall direction of the Physical Research Laboratory (PRL), Ahmedabad, till the sudden demise of Dr Sarabhai who was both Director, PRL and Chairman, ISRO. PRL was under the Department of Atomic Energy (DAE) which had considerable freedom from the "needlessly inelastic rules" of other Government Departments through the Atomic Energy Commission (AEC) structure. The elements of a profile for the decade 1970-1980 for the Indian space programme are elaborated in a document of the DAE (DAE 1970). The objectives and targets fixed in this profile had considerable impact on the activities of ISRO during the 1970s and 1980s.

The annual budget of ISRO grew to about Rs. 10 crores in 1972 and its manpower reached about 3000. Soon after Dr Sarabhai's demise, after a brief period of interim arrangements, the Space Commission (SC) and the Department of Space (DOS) were formed in May 1972 essentially on the same lines as AEC and DAE. SC and DOS are responsible for all space activities in India. PRL was placed under DOS but with a separate director. Prof. S Dhawan became Chairman of the Space Commission, Secretary of DOS, and Chairman of ISRO, and remained so till the end of September 1984. The rapid growth of space activities and the implementation of major projects occurred around the mid-seventies. The trend continued subsequently. This article deals with some elements of the management of the Indian space programme during 1972-84.

\section{Some major eyents}

For a reasonable understanding of the activities and achievements of the programme during 1972 to 1984 , the annual reports of DOS, placed in Parliament at the end of every financial year, can be consulted. Some major events are listed here.

1972: The Department of Space and the Space Commission set up by the Government of India to promote the development and application of space science and technology for identified national socioeconomic tasks. Prof. Dhawan takes charge.

1972-76: A number of airborne remote sensing experiments conducted for surveying earth resources.

Several indigenous sounding rockets were tested and flown for scientific experiments. A number of elements of solid propulsion, propellant and avionics systems developed on laboratory scale. Development of a launch range at Sriharikota begun. Tracking station experiments with liquid propulsion including a major technical know how arrangement with a French Company made.

1975: The first Indian satellite, Aryabhata, launched on 19 April 1975 from the Soviet Union.

1975 - 76: The first major space application programme, the Satellite Instructional Television Experiment (SITE), conducted during August 1975-July 1976 using the us Satellite, ATS-6. 
1977: The satellite telecommunication experiments project (STEP) carried out from the middle of 1977 to 1979 using the Franco-German satellite, Symphonie.

1979: The second Indian satellite, a satellite for earth observations, Bhaskara-1, launched on 7 June 1979, from the Soviet Union.

1980: SLV-3, India's first satellite launch vehicle, puts the Rohini satellite into a near-earth elliptical orbit from Sriharikota on 18 July 1980.

1981: India's first experimental geo-stationary communication satellite, APPLE, successfully launched by the European Space Agency's (ESA) Ariane launch vehicle from Kourou, French Guyana, on 19 June 1981. India's second satellite for earth observation, Bhaskara-II, launched from the Soviet Union on 20 November 1981.

1983: The second developmental flight of SLV-3 successfully conducted from Sriharikota on 17 April 1983 and RS-D-2 satellite orbited. INSAT-1B, India's multipurpose domestic satellite, launched on board USA's space shuttle, Challenger, on 30 August 1983. A major national seminar to define National Natural Resources Management System conducted, arriving at a national consensus preparing ground for the Government decision on NNRMS made in early 1985. 1984: The first joint Indo-Soviet manned space mission launched on 3 April 1984. Prof. Dhawan retires in end-September 1984 and Prof. U R Rao who was Director, ISRO Satellite Centre, takes over the same unitary structure from 1 October 1984.

\section{Description of some important managerial aspects}

The annual budget of DOS which was around Rs. 10 crores during 1972 increased to about Rs. 100 crores during 1984. Manpower grew from about 3000 in 1972 to about 13,000 in 1982. A number of small units situated in and around Trivandrum were organised into a large Centre and called the Vikram Sarabhai Space Centre (VSSC) in 1972 and placed under a director. Similarly a number of smaller units located at Ahmedabad were brought under the Space Applications Centre (SAC). An ISRO Council consisting of centre directors, Director PRL and senior officers of the DOS secretariat was formed. This has provided a symbolic link as well as a forum for participative management between the Department which has the Government's powers and the centres which execute the jobs. It should be noted that in the normal parlance of traditional government departments, ISRO's centres and units would be 'subordinate' or 'attached offices', words which are not, however, prevalent in ISRO and DOS. Such participative management, jointly evolved between those who wield administrative powers and the executing agencies, is an important feature of the management of the Indian space programme.

A project for India's first launch vehicle SLV-3 was organized under VSSC during 1973 , with a unified project team while retaining the elements of a matrix structure in the specialized divisions of VSSC. Some projects relating to launch vehicles were also organized at Sriharikota which later led to the formation of the SHAR Centre. Similarly a project for India's first satellite, which was subsequently named Aryabhata after launch, was formed at Bangalore under the overall direction of VSSC; the infrastructure built for the satellite projects led to the formation of the ISRO Satellite Centre (ISAC). The National Remote Sensing Agency (NRSA), an 
autonomous society set up under the Department of Science \& Technology (DST) in 1975, was transferred to DOS in December 1980, placing major remote sensing efforts under the single umbrella of DOS. In the eighties some smaller units were "spun off" from the major centres of ISRO.

Having core teams responsible for the major, well-identified projects, with tasks being executed by different centres/units of ISRO became an important factor in ISRO management from the late seventies. Partly for reasons of participative management and partly for reasons of technical complexities requiring a multi-disciplinary approach, various inter-centre management boards/councils were formed; some of these have executive functions, some have advisory roles. All the projects have a lead centre named for their execution. For example, vSSC is the lead centre for launch vehicle projects, ISAC for satellite projects. In addition, Indian industries execute major work packages as a matter of ISRO policy. This factor adds further complexities of contract management in addition to the internal technical and managerial coordination needed within the ISRO centres. The SLV-3 project had about 40 such industrial "work centres" and for the Polar Satellite Launch Vehicles (PSLV) the number has increased five- or six-fold.

In addition, the units of the space programme which started functioning in Ahmedabad and near Trivandrum in the early sixties, have now spread to a number of places in the country (see figure 1).

Yet another important feature in the management system, which emerged during the later half of the seventies and intensified in the early eighties, is the growth and coordination of joint programmes with the users of space applications. One important example is the operational multipurpose Indian National Satellite Project, INSAT-1. Such user interfaces add a newer dimension to the already complex management structures of the projects. Apex level user coordination bodies such as the INSAT Coordination Committee (ICC) and the Planning Committee for the National Natural Resources Management System (NNRMS) were also formed.

Coordination of efforts in space sciences took a newer shape through the Advisory Committee on Space Sciences (ADCOS) a brief report on which is given by ISRO (1987a).

The responsibility for the overail programme which is executed through a complex network of centres, projects, industries etc. still vested with a single person who held the positions of Chairman Space Commission/Secretary DOS and Chairman of ISRO. This is considered to be effective in combining various decision-making levels-technical, managerial, administrative and policy-makingthus cutting down delays. To assist the top decision maker, besides the usual secretariat of DOS, an ISRO Headquarters consisting of scientists and engineers was formed; these units also played a role in the overall programme management and in ensuring effective internal and external linkages. There are also a number of standing and transient Committees which assist in coordination. While it is difficult to describe these functional or hierarchical linkages even for one year or for one project because of the evolutionary and dynamic nature of these linkages, an extremely simplified organisational chart is shown in figure 2 (reproduced from one of the recent annual reports of DOS). Since the interrelationships and linkages are complex and time-varying, consensus management has been mostly resorted to in decision-making through Committees, Boards, Councils etc. 


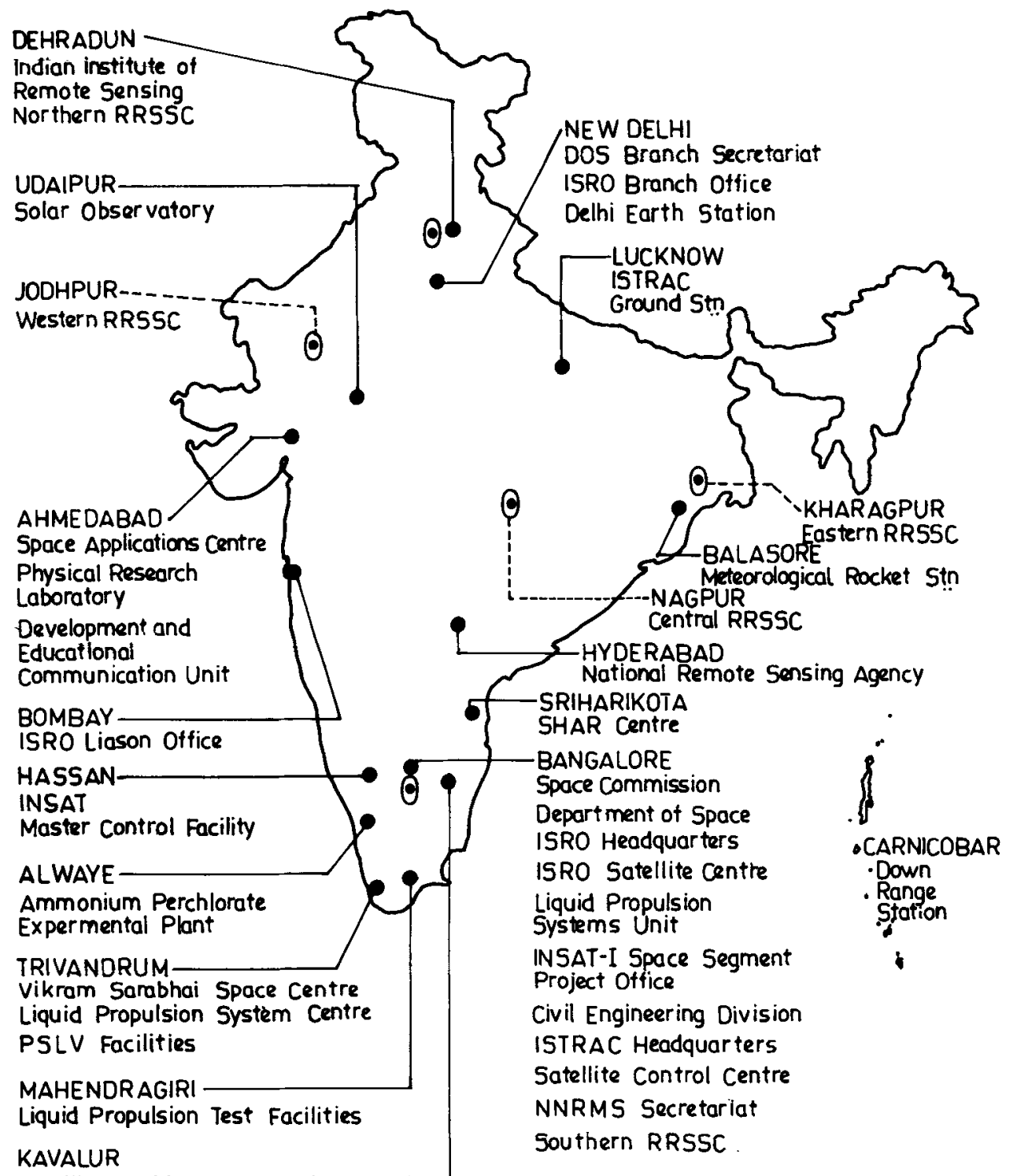

Satellite Tracking and Ranging Station]

\section{ORRSSCs under formation}

Figure 1. Establishments of the Department of Space.

The budget formulation within ISRO has since 1977 absorbed many features of zero-based budgeting. This approach has also been used as a tool for programme management. DOS has considerable freedom in financial management and has delegated substantial powers to the centres and projects.

Regarding the promotional avenues of scientific and technical personnel, which include technicians, ISRO/DOS has a merit promotion scheme broadly derived from DAE. Under this scheme a person after a prescribed number of years can be 


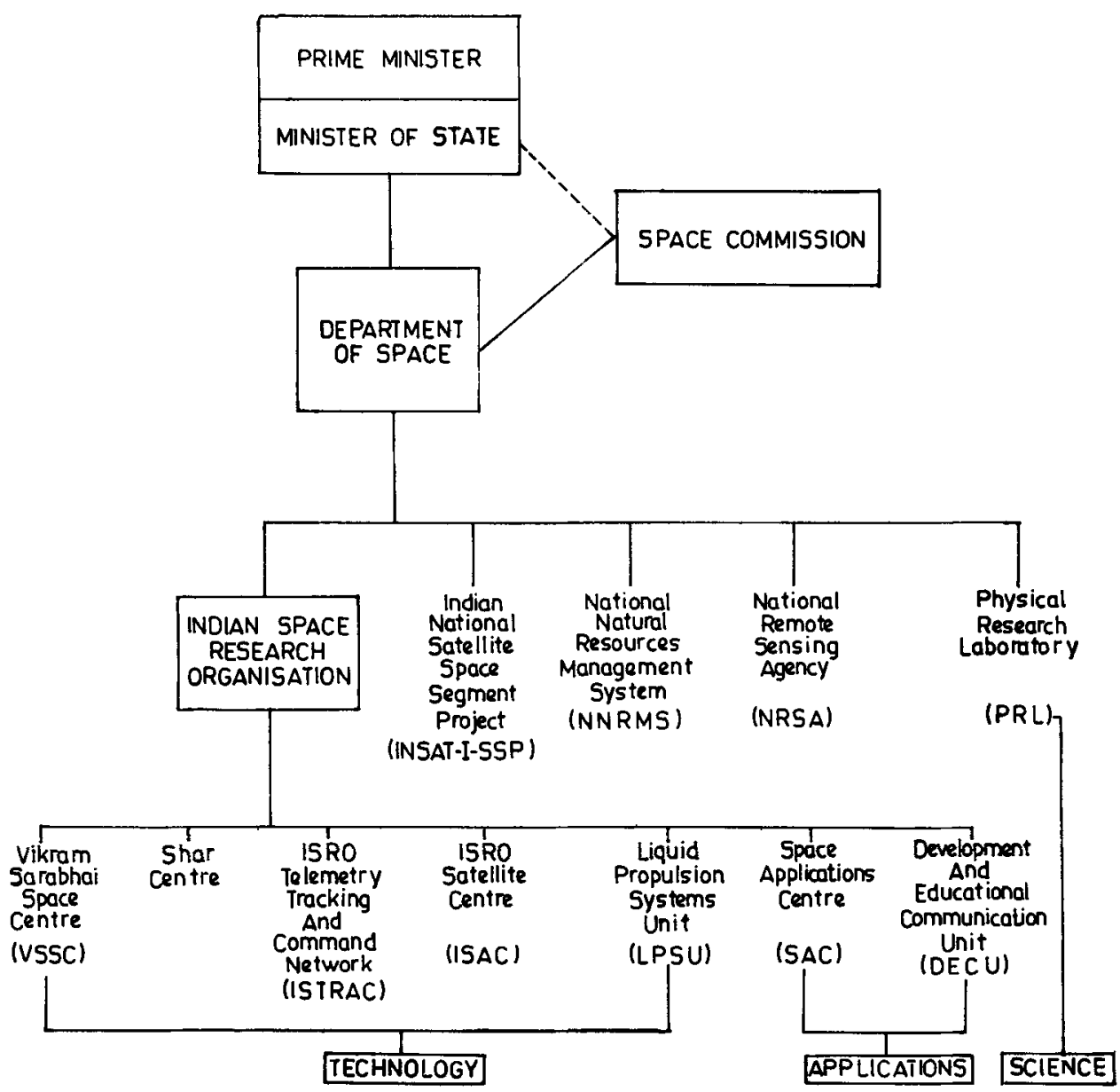

Figure 2. Organisation of the Department of Space, India.

reviewed for promotion and promoted irrespective of availability of vacancy. This system is nowadays called "flexible complementing". The majority of ISRO scientists and engineers are still young and may average around 35 to 40 years. The age distribution however may have a sharp "bunching effect" because a large number of personnel were recruited during the $60 \mathrm{~s}$ and early $70 \mathrm{~s}$ after which the rate of induction has gone down.

The Indian space programme's partnership with the Indian industrial sector is organized under four closely linked fronts, viz., technology transfer from the space programme to industry; consultancy by ISRO to industry; utilization of the industries' own technology potential and expertise by ISRO; procurement of goods and services from industry for the space programme. From the mid-seventies the partnership with the industry on the above lines was stressed as a matter of policy and activities and projects of the space programme were accordingly oriented. While 3 technologies were licenced in 1977 by ISRO the cumulative total in 1984 was 88 , with the figure in 1986 being 129 . The annual flow of funds from the space programme to Indian industry was about Rs. 13 crores during 1977-78 and has 
reached a level of about Rs. 119 crores in 86-87. Further details may be seen in the special publications by ISRO (1987b) and Sudarsan \& Sridhara Murthy (1987).

Since 1974, ISRO has instituted a formal system for supporting extramural research funding in the academic system of the country under a programme called RESPOND. Some details can be found in an ISRO publication by Ananth (1985). The technical review systems in ISRO's projects also utilized the expertise of personnel from academic institutions.

\section{Profile for the decade $1980-1990$}

A comparison of the 1970-80 decade profile for the space programme with actual achievements would indicate that the basic goals have remained the same. However, the details about the proposed projects were sparse in the original profile; it would appear that a few additional projects, not anticipated earlier, have been added during the execution of the profile. Funding for the profile period has been more than the figures projected earlier and the time-schedules have been different. The actual realization of events has taken place a few years after the milestones indicated earlier. But on the whole, targets have all been realized fully. During 1981, DOS also presented a profile for the period 1980-90 wherein the stress has been on transition to operational and semi-operational space systems to meet the country's requirements. The programme was graduating from minor projects to major ones; the projects are applications-driven; and the linkages between projects have become more complex. The integrated nature of the programme becomes more apparent. Further details can be seen in the article by Dhawan (1978), the decade profile 1980-90 given in the DOS (1981) document and the paper by Dhawan \& Rao (1982).

\section{Discussion on project and programme management systems}

In a recent publication by Dhawan (1985) on "Application of space technology in India" a glimpse of the application of space technology in India is provided. The publication also addresses the choice of technology, the risks involved, and the necessity to sustain an Indian viewpoint throughout for larger socioeconomic purposes. It gives some clues to the policy formulation which has been marked by a distinct continuity in the objectives, goals and directions.

When Prof. Dhawan took charge of the programme about 10 years after its inception, he amplified on the basic goals and objectives set up already. He has evolved mechanisms and structures to implement the decade profile of 1970-80. Thus the organisational forms that evolved during the growth of the Indian space programme during his chairmanship contained some elements dictated by programmatic choices made earlier as well as elements which were needed to handle a growing, dynamic programme. To a certain extent it was influenced by the practices of DAE. To separate out these elements, if it were at all possible, would require considerable research. Research articles on the working of the detailed management systems of the Indian science and technology organisations or programmes are practically non-existent. The reasons are manifold: the organisations are perhaps busy with their programmes; there is a fear of disturbance of the 
existing living systems; and the complexities of Indian public life add further inhibitions to data gathering and analyses. ISRO has not been an exception to this phenomenon. Therefore any attempt at description and analyses of the management system of the Indian space programme can contain many elements of the subjective biases of the author(s). This paper may also contain such biases. It is hoped that further studies suggested in this paper can be conducted in depth. Such studies could be good contributions to the Indian management literature.

In the early seventies, the implementation of larger projects like SITE, SLV-3 etc. have necessitated large multidisciplinary teams. This requirement has been met by integrating a number of existing smaller units into major centres located at Ahmedabad and Trivandrum and providing a fairly large project team. In case of the Aryabhata project, while some experienced personnel were drawn from the centres, a new geographical location was selected and an almost fully self-contained project team was formed at Bangalore. The management approach to these projects formed around the same period had significant differences, partly because of the nature of the then existing teams and their activities. Thus one sees in the management approach an ability to adopt new systems without being constrained by standard patterns. Such a trend continued even at later stages though the degree of uniformity in patterns of project management structures has increased considerably. With the approval of a number of projects like Bhaskara, APPLE, etc, the patterns adopted were in the nature of compact core teams, identified lead centres, multi-centre activities, matrix forms within centres to deliver sub-systems to the projects and so on. The multiplicity of such linkages and controls also tended to reduce the singular authority on the projects by the centre directors from the levels that existed in the early seventies. However the number of activities in the centres increased, making intra-centre coordination more complex and difficult. The conversion of ISRO into a government body in 1975 reduced certain flexibilities in procedures that existed earlier.

While from the sixties till 1972 the Chairman of ISRO was the main authority for decision-making, a number of subsidiary authorities for executing decision-making with fairly well-defined hierarchical structures emerged from 1972 onwards. Their number increased considerably thereafter with final organisational structures in the centres and projects. The dynamics of the programmes as they grew further especially with multi-centre projects being executed simultaneously during the seventies and the eighties exerted pressure on these authority structures. While consensus management helped a great deal in avoiding serious breaches, the need for conflict resolution in the speedy time-frame required for projects tended to raise the problems to the higher levels of authority, which in the ultimate rested with the Chairman, ISRO/Secretary, DOS. Since such a raising of the levels of decision-making can have negative effects on the managerial delegations given to the lower levels of the authority structures, formal and informal review systems of the projects and the programme activities by superior authorities especially by Chairman, ISRO, with the participation of a large number of technical teams drawn from different levels of ISRO systems and sometimes from outside ISRO provided an outlet for resolving conflicts in a speedier time-frame without seriously damaging consensus formation mechanisms and without making the lower levels of decision-making systems ineffective. The role of the Chairman, ISRO, in such a 
process is both crucial and delicate. Characterization of specific elements of the chairman's role can be an interesting and important research topic. The fact that Prof. Dhawan has very successfully carried on these roles over a long period is borne out by the achievements of the programme and the momentum it gathered during his chairmanship.

The ISRO review systems during the seventies and eighties resulted in generation of formal documentation of systems engineering, design, quality assurance, test procedures etc. Presentations through audio-visual means were also, used as a means of technical communications. Such a system of formal technical documentation and presentations has become a built-in part of the management processes of the Indian space programme. It has many useful features for the management of large systems.

Another important stress exerted by the major organized projects of the space programme has been on the $\mathrm{R} \& \mathrm{D}$ activities of ISRO and studies on future systems. Since the projects compete for ISRO resources for meeting their targets, activities which were not "visible" tended to be ignored. To minimize the effects of such pressures which affect the future of the space programme, some technology development projects (TDPS) were formulated. Reviews of some major R \& D areas by Chairman, ISRO, were organized to get clarity and also to provide "visibility" to these activities. Study groups for defining future systems were formed drawing part-time personnel from ISRO centres/projects. The results of many of these efforts are mixed. A detailed study of these activities and their results with a view to get clues on the managerial strengths and weaknesses of ISRO in handling these R\&D items and future studies, would be very valuable.

With respect to the interfaces with the user agencies relating to communications, television, meteorology, natural resources managements etc., right from the stages of formulation of approach up to the stages of actual joint execution, the systems evolved by ISRO since the mid-seventies have been unique and have many positive features. These systems and mechanisms evolved by Prof. Dhawan can be considered as one of the high points of his contribution to the national science and technology (ST) scene. The fact that these systems of linkages, coordination and implementation exist today, in operational forms for INSAT and in a semioperational way for resources management, is worth noting. The evolution of these interfaces and their sustenance in the operational phase has important lessons applicable to a number of other areas in the country and perhaps a serious study would be useful.

Similarly Prof. Dhawan's efforts to develop a partnership between Indian industry and the Indian space programme are an example of his foresight regarding the needs of operational systems in the country, especially when the programme has to be self-reliant and viable based on indigenous efforts. While he might have derived his clues from the developed countries, a number of unique organisational linkages such as formal memoranda of understanding with major industries, formation of compact groups in ISRO to interface with industries etc., are his important contributions to the Indian scene. From the trend of increasing partnership with industry, it can be inferred that in the years to come the benefits to industries themselves will form one of the important justifications for the Indian space programme besides its direct applications. The managerial complexity 
resulting from such a major role by the Indian industry will have considerable impact on the organisational forms of management adopted by ISRO/DOS so far.

As far as linkages with the educational system such as academic institutions, University Grants Commission (UGC) etc. are concerned, a number of managerial innovations have been tried since 1974 to promote university research in space technology and applications. It should be noted that as an educator himself, Prof. Dhawan has been keenly aware of the mutual benefits that can be derived from the Indian space programme and the educational system. While the participation of personnel from the academic system in the reviews of the technical activities and in the study groups of ISRO and for specific extramural research has increased considerably since 1974 , the objective of creating major centres of excellence in research in space technology and applications in a number of places in the country has not been realized. This may be partly due to the fact that ISRO, as a matter of policy, refrained from opening new centres of education and has tried to draw upon systems from the existing institutions. It is also possible that ISRO R \& D managers at the centres/units were too preoccupied with their immediate tasks to devote attention to nurturing these links. A few joint space technology cells formed recently with such a framework in view have started functioning. In the area of linkages with the academic systems, the Indian space programme would need to devote concerted attention in future to strengthening its $R \& D$ base which otherwise has begun to get eroded by the compulsions of the execution of multiple major projects and also due to the demands of running operational national space services.

Figure 3 shows some of the major features of and events in the management of space programmes described above as it evolved since the $1960 \mathrm{~s}$.

\section{Discussion on personnel management and schedule management}

While in an organisation, one has to deal with all personnel, in this article only ST personnel are addressed. The promotional policy has been described in an earlier section. By and large, ISRO has not adopted any formal training programme of the newly recruited or existing personnel. Induction of personnel to higher levels of managerial hierarchy, from outside ISRO, has been extremely limited since 1972 as also the "loss" of such personnel from ISRO to outside organisations. The efforts since 1972 have been the consolidation of the management systems around the existing personnel with suitable restructuring tailored to its needs. This may be partly conditioned by the fact that the organisation in 1972 was already about 3,000 strong and nuclei of managerial positions existed albeit in a rudimentary form. The recruitment of scientists and engineers is predominantly at the lowest level; young persons fresh from colleges and universities are recruited. They grow to fill the higher levels of hierarchy. The trend continues. Formally ISRO procedures allow for lateral entry at any level and also transfer of personnel between any centres/units of ISRO/DOS. In actual practice these are very limited probably due to the compulsions of the projects and also due to the growth of ISRO. There are some signs of slowing down of the growth rate in manpower since the 1980s. Givęn this slowing down and the ageing of the organisation, and also in view of the flexible complementing scheme of promotions, the hierarchical levels built up already are likely to be stressed further, calling for changes in the existing organisational structures. While 
major changes have not taken place during 1972-1984, some smaller units were formed during the eighties. Some of these were necessitated partly by the needs of technical activities. Another important feature of personnel management in relation to programme management has been the maintenance of high morale in ISRO despite a number of initial failures or problems in the projects whether it is SLV-3, Aryabhata, Bhaskara, APPLE or INSAT-1A. A team of dedicated personnel have kept up their steady march towards the set goals and targets. It would be interesting to study the motivational factors behind this fact. Is it because of the challenge of space research, or the charm of the Chairman of ISRO and his long tenure, or due to the better programme management systems? Or the better promotion avenues for ST personnel in ISRO? Or due to availability of progressive and flexible administrative, financial and purchase rules in ISRO? Or, if a combination of these, in what proportion?

An analysis of the schedule management of the Indian space programme reveals many interesting features. While the time-targets projected in the decade profile of 1970-80 cannot be taken as specific items for comparison with actual events, by and large achievements of targets for satellites and launch vehicles have been well within the overall profile targets and subsequently stated time-schedules. It is difficult to assess specific slippages in project-schedules because the detailed milestones were evolved from 1972 onwards through specific projectisation. An impressive feature of the actual events from 1975 to 1984 will indicate that each year has at least a major milestone and no year is without a major event. This could not have been a mere accident but only an indicator of a carefully planned and executed programme which has aimed at optimal utilization of human, financial and other resources. In addition such events helped in sustaining the overall morale of the organisation and also in generating a feeling of oneness. A detailed analysis of utilisation of major rocket test facilities, propellant production plants etc, would further prove the fact of such careful planning; long periods of idling as well as heavy overcrowding in a few months have been avoided. This speaks well for the management system which was able to orchestrate various levels of the system in planning and execution, in the midst of technical and other uncertainties including a number of initial failures.

\section{International cooperation}

The Indian space programme has drawn upon, since its inception, benefits from the cooperative programmes offered by the developed countries to build up its trained manpower pool and to conduct a number of experiments in space sciences and applications. In some limited cases, 'licenced production' has been resorted to. In some cases technical know-how has been obtained, mostly paid for through the services of expert ISRO manpower and the supply of certain finished products to the supplier of the know-how. Since the late seventies, the international cooperation has increasingly acquired the level of "equal partnership". This has been mainly due to the fact that the Indian space programme has been steadily moving towards the goal of self-reliance and has also grown in size. The Indian space programme is in the unique position of having active and continuing cooperative links with a number of major space agencies in USSR, USA, Europe, France, West Germany etc. 

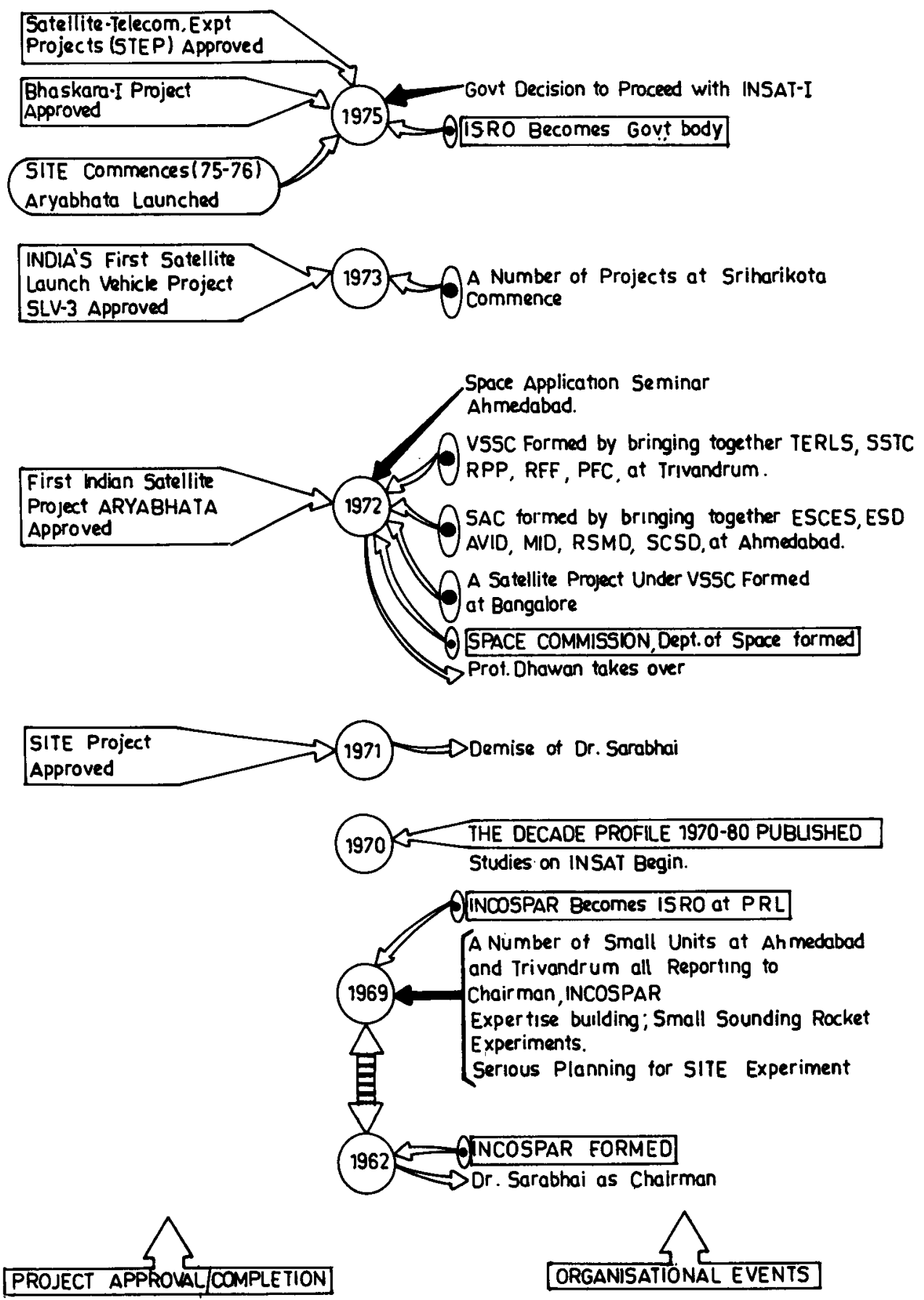

Figure 3. (See facing page for caption.) 
FIG:3(contd)

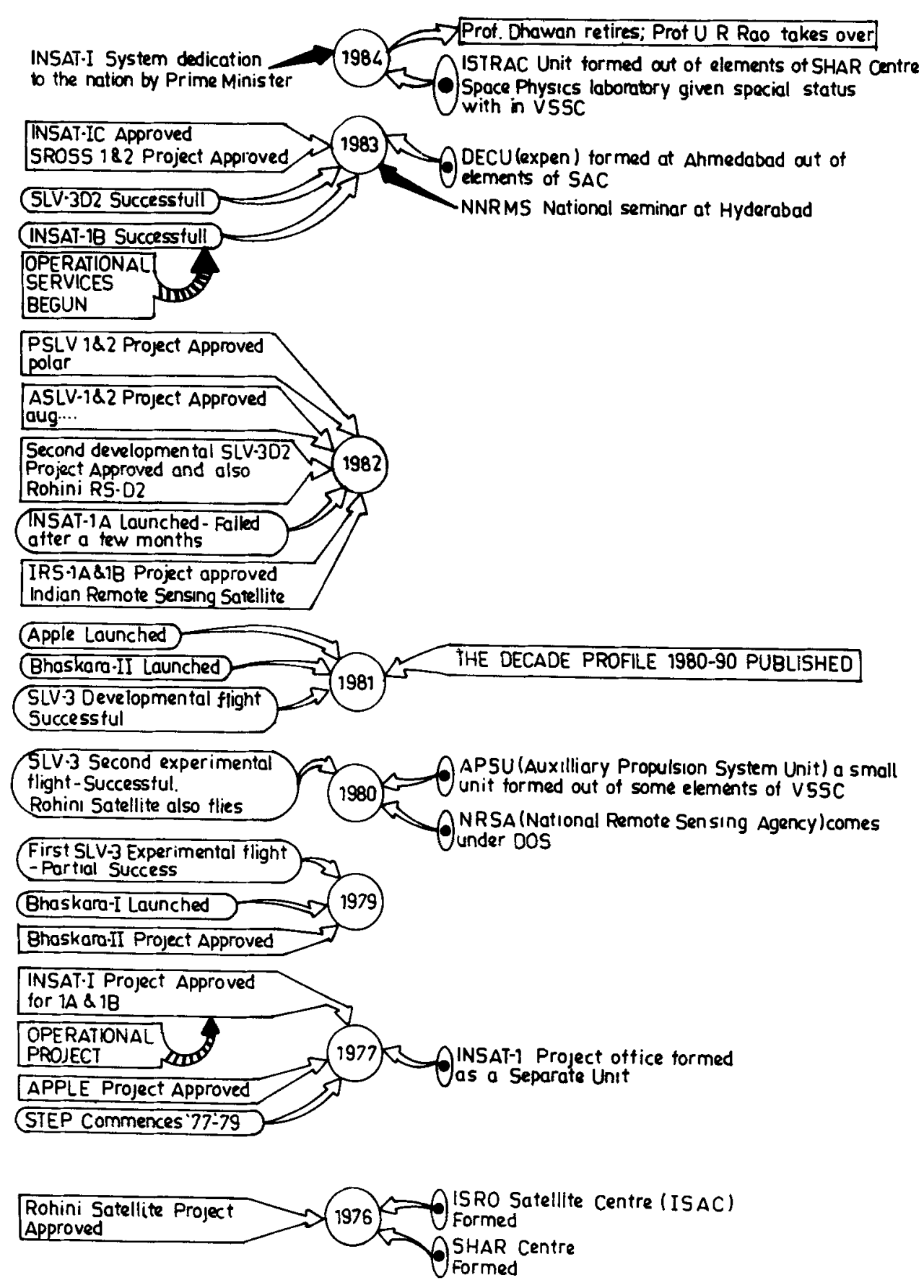

Figure 3. Some major organisational features and project events of the Indian space programme. 
On the commercial front, a number of selected subsystems and equipment required for the Indian space programme have been purchased from abroad. Efforts have been made to reduce, as far as possible, the import component. The foreign exchange component of the budget of the space programme has ranged between 25 and $30 \%$, approximately.

In the case of the INSAT- 1 system, procurement of the space segment has been from abroad. The launches of the bigger ISRO satellites have been made with the help of foreign launch vehicles from spaceports abroad.

The pressures from the national operational services, the increasing commercial trends of the space services of many developed countries, and the competition between them for world markets can have an impact on the Indian space programme and therefore its management. On the other hand, the growth of the Indian space programme in size, its move towards operational systems, and the growing role of Indian industry as a major partner in the space programme can lead to India entering world markets through commercial channels as well as through cooperation channels especially because of its stated goal of sharing its experience with other developing countries. Some aspects of Indian views on self-reliance are given in an article by Rajan (1984).

The impact of these developments on the management systems of the Indian space programme could be considerable. Presently one can only speculate on possible impacts since the actual experience is limited.

\section{A comparison with the management structures of other countries}

It is not possible to address such a comparison in any depth. The management of the Indian space programme in an overall structural sense has a number of similarities to the evolution of the structure in the National Aeronautics and Space Administration (NASA) of USA and in the European Space Agency (ESA). But one should also note that ESA and NASA are also undergoing major structural changes. Placing all activities felating to the space programme, such as policy formulation, $R \& D$, product development, project execution and the responsibility for operational space services to the users, under one single organisation led by a single person with unitary authority, is unique to India. While it has helped in the evolution of an integrated programme in a rapid manner with limited resources, it should be noted that the impact of the Indian space programme on various walks of life in the country, has just begun to consolidate, thanks to the major achievements of the programme during the seventies and the eighties. The space applications and therefore operational services in the country are likely to grow very rapidly during the late eighties and in the nineties. It is difficult to forecast the type of systems most suited under such circumstances. With the participation of major user agencies in the country in the operational applications of space activities and the growing partnership of the Indian space programme with industry and other institutions, one can envisage the emergence of some new forms of structures in India, similar to those which exist in the USSR or Japan for their space activities, with specialized institutes and industries dealing with specific standardized subsystems or components and the integration taking place through project and 
programme structures; $R \& D$ may be carried out to a large extent in the university system or in special laboratories.

\section{Concluding observations}

Some questions on the future

Any management system is conditioned by its past, and has its impact on the future. Some of the possible dynamics that may be imparted by the management of the Indian space programme during 1972-1984 on future systems, can be a topic for detailed study in itself. Some pointers and also some questions posed are presented here.

By absorbing the objectives set forth in the 1970-80 decade profile and by organizing well-structured projects and activities to realize the objectives set forth earlier without being needlessly rigid about the details, Prof. Dhawan demonstrated the strength of continuity of policy in the execution of the Indian space programme. By building the management structures mostly around existing personnel and units, he again stressed the continuity aspect. However, during the period of his chairmanship, there were a number of newer units established in different places in India. Integration of existing smaller structures took place during the early seventies, building out of them major structures called centres/projects, with authority structures being more unitary than those that existed before. Such a process also led to the reduction of direct executive decision-making by the Chairman, ISRO. Simultaneously the newer units/projects which were established grew in a few years to form new centres, reducing the dominance of the centres established earlier. The projects placed under the centres also grew in complexity and were of an inter-centre nature drawing from all the ISRO centres as against the earlier ones which were predominantly executed in a single geographic location. Such inter-centre projects blurred the unitary authority of the centres over their projects. Industrial contracts added additional dimensions necessitating the involvement of contract/finance managers, such as senior officers of the DOS Secretariat, in the programme management structures. Though the delegation of financial and administrative powers to the centres and projects was considerable, the multiplicity of ISRO/DOS centres and units, and the magnitude of inter-centre projects executed by ISRO, led to complex and fast-changing functional and hierarchical relations, causing confusion in the earlier simpler forms of locally placed unitary authorities such as Centre Director/Project Director etc. This factor contributed to the increase of the mediatory role of Chairman, ISRO and therefore the headquarters.

While many facets of such roles of Chairman, ISRO and the subordinate authorities have been successfully adjusted from 1972 onwards to meet the requirements of the Indian space programme so far, it should be noted that the programme is growing at a rapid pace especially with respect to the delivery of operational services. Considerable increase in the decision-making authority at the lower levels of the management structures without affecting the overall integrated coordination between various elements of the programme will therefore become increasingly necessary to avoid stresses in the higher levels and to speed up 
decision-making. The challenge to the space programme in the coming years will be to strike a judicious balance. How many useful clues will be available from the earlier experience of the flux of "change and continuity" is a matter for detailed study.

The user coordination systems built up since the mid-seventies as described earlier are remarkable, and could perhaps continue for some years with necessary changes required by new operational services. A constant review would be required especially because of the rapid growth of the applications, and the possibilities of introduction of newer services. Another challenge in the future would be to maintain an "openness" with regard to the introduction of newer patterns and newer systems. The successful 'marriage' of the $R \& D$ culture of ISRO with the rigours of operational services could come under strain unless watched carefully during the rapidly growing phase of the operational sector.

It would be an understatement to conclude that the management of the Indian space programme during the period 1972-1984 by Prof. Dhawan has been a unique and successful one, with very few parallel records in the world, and has a number of lessons in it for the future of the Indian space programme as well as many other sectors of Indian science and technology. It is, therefore, an excellent "field" for management researchers.

Regarding what can be in store for the future, an extract from an article by Dhawan (1985) will be in order:

"One has however to contend with change. Over the 25 years a new generation has grown up in India. Those who made the selection of space technology and provided the inspiration, initial momentum and enlightened political support have passed into history. How will the new generation of scientists, political leadership and the people at large see the social goals and the role that should be assigned to space technology?

As the experimental phase transitions into space operations and the lives of millions of Indians can be influenced and affected, people are bound to ask, 'Is this for our good?' The tools have been built, how will they be used? Will TV, now that it can reach the millions, help them? Centrally beamed programmes reach every nook and corner but they are one way-what is the feed back? Don't the teachers want to listen to the students? Can we not devise a two-way system? Will the resource managers' decisions, armed with good and timely information, help the farmer, the urban elite or the stock exchanges? A million questions! These cannot be answered by space technology. Only people who care, can."

Some of the answers to these questions will have tremendous impact on the future management of the programme.

The author is grateful to Prof. $R$ Narasimha and Dr A P J Abdul Kalam for providing him with the opportunity of writing this article and to $\mathrm{Dr} K$ Kasturirangan for a number of useful discussions on the subject. The author has benefited considerably from the constructive criticism of A Chandran. The author, in his association with Prof. Dhawan, has been particularly fortunate in having the unique opportunity provided by Prof. Dhawan for sharing some of the excitement as well as the rigours of experience in the management of the Indian space 
programme. This article would not be complete without mentioning the great contributions of the numerous ISRO personnel-scientific, technical, and administrative-to the Indian space programme, without whose dedicated efforts it would not be what it is today.

\section{References}

Ananth 1985 A ISRO sponsored Research Programme (RESPOND), ISRO special publication ISRO-RESPOND-SP-13-85

DAE 1970 Atomic Energy and Space Research, A Profile for the decade 1970-80, Atomic Energy Commission, DAE, Government of India

Dhawan S 1978 Proc. Indian Acad. Sci., C1:1-26

Dhawan S 1985 Application of Space Technology in India, Aryabhata Lecture, Indian National Science Academy, August 2, 1985, Publication Indian Space Research Organisation, Bangalore

Dhawan S, Rao U R 1982 The Indian Space Programme, 13th International Symposium on Space Technology \& Science (ISTS), Tokyo, June-July 1982

DOS 1981 Space Research and Development: Profile for the decade 1980-1990, Department of Space, Government of India

ISRO 1979 Sarabhai on Space-A selection of writings and speeches, September 1979, Indian Space Research Organisation, Bangalore

ISRO 1987a ADCOS, Advisory Committee for Space Sciences, Report of Activities 1980-86, ISRO special publication, ISRO-ADCOS-SP-28-87, March 1987, ISRO, Bangalore

ISRO 1987b Space-Industry Programme-1986, A partnership in progress, Technology Transfer Group ISRO HQ. ISRO special publication ISRO-TTG-SP-27-87, March 1987

Rajan Y S 1984 Self-reliance in the Indian Space Programme and sharing of experience, Proc. of Workshop V, Promotion of Space Research in Developing Countries. COSPAR XXV Plenary meeting 25 June-7th July 1984, Graz, Austria

Sudarsan P, Sridhara Murthy K R 1987 India's Space Programme \& Indian Industry-a partnership in progress, ISRO special publication, ISRO-TTG-SP-26-87, March 1987 